\title{
4
}

\section{Partnering along the construction logistics chain}

Pahkala S., Nyberg T., Wegelius-Lehtonen T.

Helsinki University of Technology, TAI Research Centre

P.O. Box 9555, 02015 HUT, Finland

Tel. +358-9-451 3968, fax +358-9-4513665

E-mail: samuli.pahkala@hut.fi, tom.nyberg@hut.fi, tutu.wegelius@hut.fi

\begin{abstract}
Increased requirements for quality, costs and speed of the construction projects have created need for new means of controlling the construction process. Partnering is an answer to this need.
\end{abstract}

Partnering in the construction industry has involved main contractors together with clients or sub-contractors. This paper widens the scope to suppliers.

A case study is presented to highlight the important aspects on starting a partnering relationship and learning from it.

\section{Keywords}

Partnering, construction industry, logistics, organisational learning

\section{INTRODUCTION}

The objective of this paper is to present a method for project partnering in construction logistics. Project partnering can be used as the basis of a long term strategic partnership and also autonomously as a method of developing processes. A case study of project partnering in a building material supplier group is presented in this paper. 
The concept of partnering has reached the construction industry since the late 1980 's together with the quality movement. Historically price has been the criteria for selecting suppliers. This has often resulted in poor quality and increased overall building costs. While purchasing price no longer is the only issue new ways of thinking and acting are needed. Partnering is an answer to this need.

There has been some discussion about partnering in the construction process. The discussion has mainly concentrated on partnering 1) between the client and the main contractor and also 2) between the main contractor and subcontractors. This paper discusses partnering between the building material supplier and its customer, main or subcontractor.

\section{PARTNERING IN THE CONSTRUCTION INDUSTRY}

The most used definition of partnering in the construction industry was presented by the Construction Industry Institute of the USA in 1991 (CII 1997, Loraine 1994, Crowley et al. 1995, Matthews et al. 1996):

Partnering is a long-term commitment between two or more organisations for the purpose of achieving specific business objectives by maximising the effectiveness of each participant's resources. This requires changing traditional relationships to a shared culture without regard to organisational boundaries. The relationship is based on trust, dedication to common goals and an understanding of each other's individual expectations and values. Expected benefits include improved efficiency and cost effectiveness, increased opportunity for innovation, and the continuous improvement of quality products and services.

The first arrangements of partnering in the construction industry have been between clients and main contractors, starting with major process industry manufacturers (e.g. Shell) as clients and construction companies who build their numerous productions plants. Most of these arrangements have been between previously known companies. These relationships have been long term partnering extending beyond individual projects. (Loraine 1994)

More recently there has also been project specific partnering which does not necessarily aim at long term commitment. The aim is rather in the development of solution methodology on a certain construction project (Loraine 1994). The aim can also be at learning partnering procedures as basis for a future long term partnering relationship. Matthews (1996) sees that project partnering is likely to take the lead role in developing closer relationships within the construction industry. He also states that many organisations will experiment with project partnering and wait for provable, positive results before initiating any strategic partnering relationship.

Partnering relationships are not only limited between the client and the main contractor. The increasing use of subcontracting has put more stress on the subcontractor - main contractor relationship. Traditionally main contractors have 
executed most projects using directly hired labour. Nowadays up to $90 \%$ of the project value can be subcontracted while main contractor provides only project management. This is equally true in the United Kingdom (Matthews 1996) as in the Nordic countries.

There is no reason for leaving suppliers out of the partnering concept. On the contrary, suppliers have a great effect on the quality and costs of the construction process, and are therefore a tempting partner for any construction company. A construction project is closer to an assembly line than a manufacturing plant and the suppliers play a great role in providing the components to be assembled. The share of material costs is over $50 \%$ of the total building costs. In the automotive industry the share of material costs can be up to $85 \%$ of the costs of a car (Christopher 1992). In addition, the logistics costs are around $10 \%$ of the total costs of a building or a car (Finnish ministry of transportation 1995, Christopher 1992). Thus it will be profitable to establish partnering relationships with the suppliers that concentrate on the information and material flows between the supplier and customer company.

\subsection{Effect on cost}

By definition partnering aims at cost effectiveness. Cost has traditionally been a means of selecting and controlling the contractors. Clients have used cost based selecting and controlling on main contractors who in turn have used it on subcontractors. Unfortunately traditional low-bid contracting puts a premium on withholding information (Loraine 1994). Lowest prices also result in unhealthy competition where companies with insufficient expertise can enter the market with very little capital. This clearly has a negative effect on costs in the long run - the cheapest may well turn out to be the most costly (Matthews et al. 1996, Burt 1989).

These points can be altered by partnering. Information sharing and mutual understanding of costs help build the trust required for fewer long-term supplier relationship - partnering (Burt 1989).

\subsection{Effect on quality}

Quality is one of the most important aspects affected by partnering. According to Loraine (1994) there is now the view that methods such as total quality management are unlikely to be introduced successfully to projects without partnering arrangements. Quality has taken over the historical role of price as means of control in the construction industry. A carefully selected and managed supplier offers the greatest guarantee of consistently high quality, namely, commitment to the project (Burt 1989).

This change from price driven to quality driven control means radical change both in the attitudes of the purchasers and in the supplier base. In the beginning of the 1980's Xerox copier manufacturer reduced its supplier base from 5000 to 400 and simultaneously improved quality, reduced costs and shortened production lead 
times (Burt 1989). The same kind of actions are needed in the construction industry. In the beginning of 1990's a large Swedish construction company, Skanska, had a supplier base of over 30000 (Jarnbring 1994). Partnering aims at closer relationships with fewer suppliers, which is seen resulting in better quality together with lower costs (Shonberger 1986).

\subsection{Effect on innovation}

Increased opportunity for innovation is another aim of partnering by definition. Partnering or virtualisation is needed to create and utilise innovations outside ones own organisation. The theory of learning organisations highlights the role of customers and suppliers as a fertile source of new ideas and information (Marquardt 1996). Customers have vital expertise on what they buy and knowing and fulfilling their expectations is essential for any business. Chesbrough (1996) sees that to commercialise an innovation profitably, a tremendous amount of knowledge from the own industry, from customers and from scientists must be gathered and understood.

To achieve a competitive edge one needs a change champion who makes sure that the innovations can be utilised within the organisation. Uncontrolled innovations only result in losing the competitive edge to somebody else (Chesbrough et al. 1996). Suppliers starting a partnering relationship have a great opportunity to offer their customers extra, value-adding services. The object, of course, is to become a preferred supplier to key customers (Boversox 1990).

\subsection{How to start a partnering relationship?}

The construction business consists of separate projects traditionally involving constantly changing parties. Although the projects are unique, there is no need to change actors with every project. The building methods and materials are always quite similar, so why should the contractors and suppliers change every time? (Wegelius-Lehtonen et al. 1995)

By definition partnering is commitment and trust, and there is not necessarily the need for a legal contract. In strategic partnering there is benefit for all parties to develop an agreement. In project partnering the goals for the specific project are drawn and agreed at a special workshop before the project (Matthews 1996). Project specific partnering is probably the most convenient way to start absorbing new ways to think and act.

A specific team is necessary for organising project specific partnering. This team is referred to the joint workshop (Loraine 1994), project team (Matthews et al. 1996) or action research team (Wilson et al. 1995). This team is needed not only for a specific project but also to catch the knowledge and to ensure that the same results can be achieved in future projects. 
Wilson (1995) recommends, that the following steps be taken on the road towards partnering:

- organising for change

- describing present state

- defining future state

- planning for change

- implementing and managing change

- institutionalising change.

These steps can be found in any organisational development handbook but they still are good to re-emphasise. The key points are that change must be planned and managed well, and that the results have to be utilised. Wilson (1995) also points out that leaders must remain committed to change throughout planning, implementation, intervention and stabilisation.

Loraine (1994) goes into more detail while he stresses the need for a formal approach on project specific partnering. This approach should specify:

- preselection process

- workshops

- champions

- facilitator

- quality

- contract award criteria

- form of contract.

\section{Preselection process}

There is a need for changing the culture to eliminate speculative bidding (Loraine 1994). This can be implemented together with quality management which often involves the formal classification of suppliers' or contractors' capabilities.

\section{Workshops}

Joint workshops of both client and contractor (or contractor and supplier) key site and head office personnel involved in the project are set up to promote culture change and teamwork. The workshops will start immediately following the contract and will continue throughout the project duration at periodic intervals and as required if problems develop. Facilitators should control the workshops but they are not involved in the decision making process. (Loraine 1994)

Matthews (1996) illustrates an example of a client-contractor project team that met every Friday during the construction project. The team consisted of the contractor's commercial, design, engineering and site management representation together with client's management, surveyor, architectural and engineering representation. 


\section{Champions}

Key persons in project partnering and in the workshops are the change champions in both organisations. They are individuals who are committed to making the partnering process work. They should also meet the facilitator occasionally outside the workshops. (Loraine 1994)

The champion is the person who identifies the project's goals, opens doors, motivates, maintains and coordinates the group. (Marquardt 1996)

\section{Facilitator}

The facilitator organises the workshops but does not take part in the decision making process. The role of the facilitator is vital in keeping the discussions away from purely contractual questions and towards maintaining cooperation and shared interest. Normally the facilitator comes from organisations specialised in behavioural sciences. An optimal mix would be an engineer with teamworking and interpersonal skills. (Loraine 1994)

In organisational development literature the outside facilitators or consultants are generally considered to be one of the key points of successful change. Other important points are management support and wide participation.

\section{Quality and safety}

Loraine (1994) notes that project partnering and total quality management share a common philosophy:

- commitment at the highest level

- unqualified focus on customers' requirements

- shared communication

- joint problem solving

- continuous improvement.

\section{Contract award criteria}

After the bidding process two or three of the most favourable bidders should be interviewed. Discussions with key personnel should clarify their knowledge and commitment to the partnering process. (Loraine 1994)

\section{Form of contract}

In addition to the traditional forms of contract there should be mutual voluntary agreements of objectives, communication, problem solving mechanism, roles of the champions and facilitators, workshops, mechanism for adjusting price, quality programme, monitoring and continuous improvement procedures. (Loraine 1994) 


\subsection{Logistics partnering}

There are numerous examples of logistics partnership in various industries. In the construction industry there is no single manufacturing plant where material flows are concentrated. This does not, however, restrict the possibility of partnering with suppliers who deliver their goods from specific sources with specific carriers.

Logistics can be seen as a system set up to meet customer service goals. We must fully understand the service needs of the various markets that we address and then seek to develop low cost logistics solutions. There should be service standards for specific customer groups. While the services are standardised they can be sold within the known order cycle time. Non-standard services result in high variation of cycle times. (Christopher 1992)

Christopher (1992) discusses supplier development teams at Nissan Motors UK. The purpose of these teams is to work together with suppliers to seek out ways in which the relationship between the two parties can be made mutually beneficial.

That is clearly partnering with suppliers. If it works in the automotive industry, why wouldn't it work in the construction industry too? After all they both are assembly based production.

Christopher (1992) sees the future challenges in logistics to be shifting:

- from function to processes

- from profit to profitability

- from products to customers

- from transaction to relationship

- from inventory to information.

All of these points fit into partnering. Actually many of them even require partnering. Or how else could you imagine operating processes in close relationship with the customers?

\section{FRAMEWORK OF PARTNERING ALONG THE CONSTRUCTION LOGISTICS CHAIN}

In the last five years a method for project partnering in construction logistics has been developed in the TAI Research Centre at the Helsinki University of Technology. Knowledge of logistics researchers and organisational development are combined to help construction companies and their suppliers to develop logistics in close cooperation with each other. The method has been developed and tested in several case studies. For the first time it is used on large scale as means of partnering in the case described later.

The method emphasises a process view over the logistics chain. Boundaries have to be crossed both inside the organisation between different functions and moreover between different organisations. All the parties along the logistics chain are involved in the partnering process. (Figure 1) 


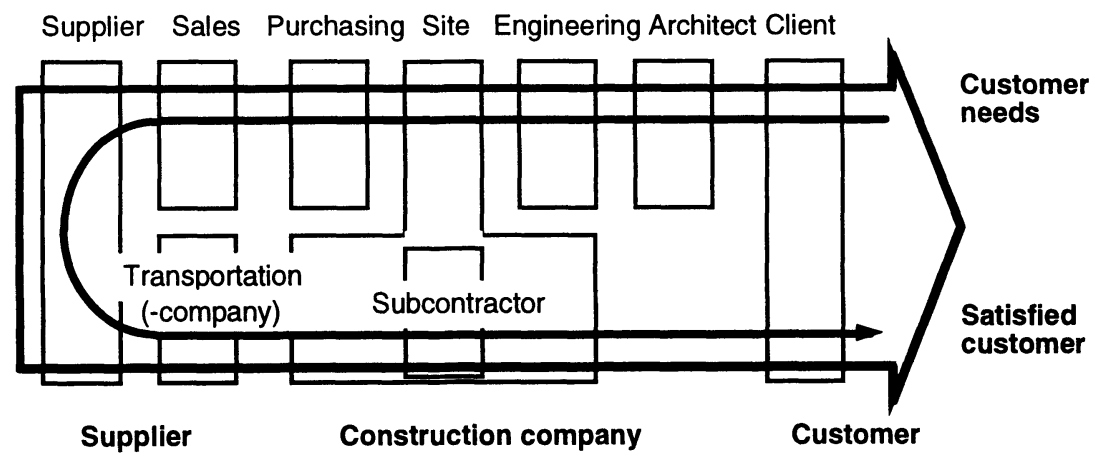

Figure 1 The order-delivery chain in a construction project.

\subsection{Participants on the partnering process}

Involvement is needed both on the operational and management levels. Operational level involvement means active participation in the workshops. Management involvement means allocating sufficient resources to partnering but also organising a high level steering group together with partnering companies. The role of management is extremely important in motivating other parties of the chain to project partnering. During the partnering the steering group meets only every twothree months to control how things are improving. The operational resources participate on the partnering workshops.

The key operational resources are:

- representatives of the site, engineering and purchasing from the main contractor

- representative of the sub-contractor (when used)

- representatives of sales, planning, production and dispatching from the supplier

- representative of the transportation company (or department if in-house)

- change champions from the main contractor and the supplier

- facilitators from an outside organisation.

Representatives of the client and architect are needed only if the supplied material involves specific architectural design. While all the parties on the orderdelivery chain are represented the possibility of sub-optimisation is eliminated. The implementability of every development action is evaluated on multiple points of view and only the realistic ones will survive. 


\subsection{The role of partnering on development}

Partnering is used only as one part on developing the order-delivery chain (Figure 2). The process starts from (1) a need for change. (2) Current situation and (3) future vision are defined before any development is done. The development actions need to be (4) tested and (5) evaluated before a wider implementation. This framework is quite close to the PDCA-cycle (Plan-Do-Check-Act) of the quality philosophy.

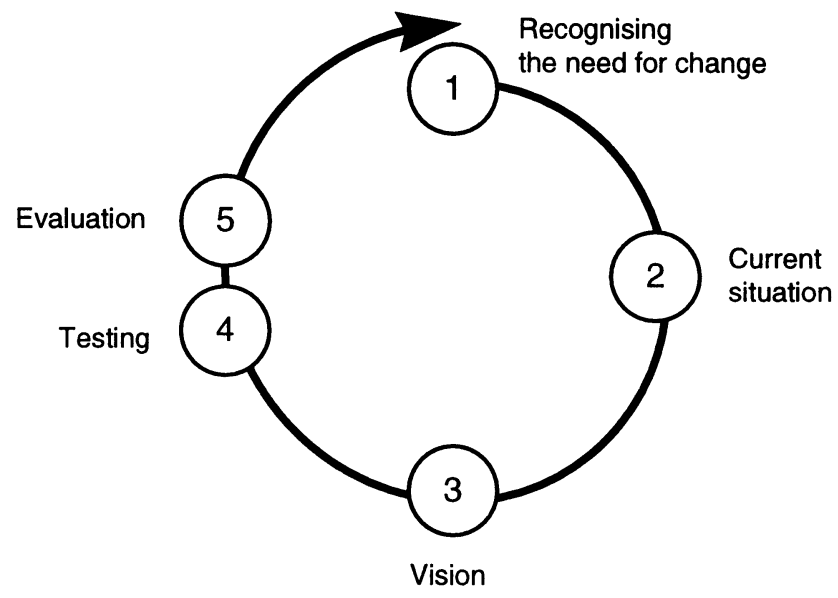

Figure 2 The development spiral.

Before starting project partnering there has to be a need for change - the reason why to develop at the first place. To know where you want to go, you also need to know where you stand at the beginning. We have used benchmarking to define the development needs and potentials on the present order-delivery chain. Based on the benchmarking results a vision for the future order-delivery chain is drawn. This acts as basis for the project partnering.

All the partnering companies are involved also in the benchmarking state which serves as motivating for the partnering. The benchmarking state reveals usually a lot of problems, small or large, along the logistics chain. These problems tend to occur at the boundaries of separate functions and organisations so no single company can solve them alone. Project partnering is definitely needed.

Project partnering is used to develop, test and evaluate new practices for the order-delivery chain.

\subsection{Partnering workshops}

The key operational persons on the project are gathered in to joint workshops. These workshops are held before, during and after the order and delivery on a specific project. On practical reasons most workshops are held at the construction 
site. But it is fruitful to held at least one workshop at suppliers factory so all the participants get a clear picture also from the activities that happen there.

A minimum of four workshops are held on the interval of two to four weeks. The duration of each workshop is two to four hours. The workshops are based on teamwork methods and open discussion. The workshops concentrate on:

$1^{\text {st }}$ Clarifying all the actions on the order-delivery chain and defining problems on the chain partly based on the benchmark results.

$2^{\text {nd }}$ Defining preliminary solutions to be developed into new practices.

$3^{\text {rd }}$ Further development of the solutions and deciding on the practices to be tested on the deliveries to the site.

Delivery: testing new practices on the site. No actual workshop although the suppliers representative might be following deliveries at the site.

$4^{\text {th }}$ Evaluating the success of the tested practices. Deciding the actions on further developing and implementing the practices.

On a case where there are multiple deliveries workshops 3 and 4 are usually repeated between deliveries.

The facilitators are responsible on arranging the workshops, but between the workshops the change champions have a major role. They are responsible on the development actions needed to develop the practices. In addition to the champions, responsible persons are named for every development action. The nature of the development actions can be either continuos, small step, improvement of existing practices or radical improvement and totally new ways to do things.

The workshops can result to not only developing and implementing the new practices but also on creating a culture and mechanism for further partnering actions between the companies.

\section{CASE EXAMPLE OF LOGISTICS PARTNERING IN A NORDIC BUILDING MATERIAL SUPPLIER GROUP}

\subsection{Background}

Since the beginning of 1996 TAI Research Centre has been facilitating a partnering project in a building material group operating in the Nordic countries. The group is young and expanding with lack of common order-delivery practices or even knowledge of the multiple existing practices. A benchmarking study has been conducted to outline the current practices on the group of seven companies (Nyberg et al. 1997). The order-delivery process between the company and its customers is regarded as a highly important process in order to gain customer satisfaction. The group has an long term aim on moving from supplying bulky construction materials towards selling more logistics services to the customers and supplying a far more ready part of the building. The benchmarking study raised two major questions related to this: 
- What kind of products and services we want to offer our customers?

- How do we build up those product and service concepts?

To answer these questions customer expectations and limitations have to be studied. Project partnering provides great means of both defining, developing and testing these product and service concepts.

The aims of the partnering project are:

- to clarify customer needs

- to develop the order-delivery chain

- to offer new well defined and standardised services to different customer groups.

The building material supplier group has various important customer groups that partly differentiate by the country. In order to cover a broad customer mix three partnering projects are carried out together with different types of customers. The case customers are: specialised sub-contractor in Finland, pre-fabricated house manufacturer in Finland and traditional main contractor in Sweden. Later on there will be one with a pre-fab house manufacturer in Sweden, and possibly various cases in Denmark and Norway. The nature of the group of seven companies provides great opportunity to conduct the study on a wide range of customer types providing a quickly a great amount of new ideas.

\subsection{Preliminary results}

The case is still ongoing until the end of 1997. Some results from the two Finnish cases and guidelines for the first Swedish case are already available. The orderdelivery chain divided to information flow and material flow. The results can be divided the same way.

Case results concerning the information flow:

- updated order form

- standard start-up meeting between the main contractor and the specialised sub-contractor

- updated assembly instructions

- standard driving instructions

- order confirmation sent to fewer locations.

Case results concerning the information flow:

- new dispatching and loading arrangements

- better control of selling the by-products

- standard services for direct delivery to the assembly place

- comparing various types of packaging

- indicating the unloading spot. 
The first Swedish case is concentrating on quite similar issues. The orderdelivery chain together with the problems is alike the Finnish cases, so the expected results are the same. It is, however, vital that the Swedish personnel can work out their own solutions for their own problems.

Some of the results, e.g. new order form and assembly instructions, can be utilised right a way on the precise partnering site. Some results, e.g. new dispatching arrangements, need more development effort before they can be widely implemented. In addition the partnering process provides valuable data for other relevant development projects. E.g. there are plans of renewing the packaging system and machine in the near future, and the partnering process gives an opportunity to compare different solutions and their effects on the factory, on transportation and on the on-site activities.

The results are measured partly quantitatively but mostly qualitatively. Most of the results make the order-delivery chain operate more smoothly. This, according to the quality philosophy, means also better cost effectiveness.

\section{CONCLUSIONS}

The power of partnering is on putting people and organisations work together in order to solve shared problems. Our experiences have shown that partnering works well also in construction logistics. On the new quality-driven construction market there is a tremendous need for means to ensure quality. For the main contractor, partnering with the suppliers is as important as partnering with the client or subcontractors. Project partnering provides a lot of practical results and is therefore very effective on implementing change - far more effective than theoretical management visions.

Because partnering aspects are new on construction business, the role of a outside facilitator is important at the start. On the long run organisations shouldn't be dependent on outside knowledge. This puts requirements on capturing the relevant knowledge on the organisation. In our case study the aim is at training the Swedish change champion to be an internal facilitator in the future cases. A local change champion will still be needed.

There were some differences between the two Finnish cases. The pre-fab house manufacturer was far more eager to develop and try new solutions than the specialised sub-contractor. This can be a results of various aspects.

The sub-contractor works with the specific material on daily basis. They have developed their own processes to be as smooth as possible under the present circumstances. If the supplier changes e.g. packaging, it has an instant negative effect on the sub-contractors performance. What they could not realise is that changes are necessary and, they had a great opportunity to affect them. There was no change champion from the sub-contractor involved in the partnering. This may be one of the major reasons for lack of motivation and change resistance. The company quality engineer will participate on further development. 
The pre-fab house manufacturer has realised the importance of partnering with the suppliers. They see their own role as the assembly line putting together the supplied materials. They have already reduced their supplier base to under 50 and believe on close relationships with the suppliers and on continuous improvement. There was a change agent from the pre-fab house manufactured involved in the partnering process. These things were fruitful for the success of the process partnering and it seems obvious that the two companies will continue towards long term partnering relationship.

The process view over the logistics chain is a vital aspect of partnering. The different actors have to realise their role as a part of the larger system. Only then they will be motivated on working towards win-win solutions. Understanding the whole process also leads on involving all the required actors in the partnering process and reaching realistic solutions.

Partnering along the construction logistics chain can gain a competitive edge but it requires innovative manners in which the parties align their operations to obtain mutual benefits.

\section{REFERENCES}

Boversox, Donald J. (1990) The Strategic Benefits of Logistics Alliances, Harvard Business Review, July-August 1990, 36-45.

Burt, David N. (1989) Managing Suppliers Up to Speed, Harvard Business Review, July-August 1989, 127-135.

Chesbrough, Henry W. and Teece, David J. (1996) When Is Virtual Virtuous? Organazing for Innovation, Harvard Business Review, January-February 1996, 65-172.

Christopher, Martin (1992) Logistics and Supply Chain Management - Strategies for Reducing Costs and Improving Services. Pitman Publishing, London.

CII (1997) www-site: http://www.adr.org/partnering_process.html, 08.01.1997

Crowley, Larry G. and Karim, Ariful (1995) Conceptual Model of Partnering. Journal of Management in Engineering, September/October 1995, 33-39.

Finnish Ministry of Transportation (1995) Logistics measures. Series B: 7/95. (in Finnish)

Jarnbring, Joakim (1994) Construction site's materialflow costs. Lund University of Technology, Lund. (in Swedish)

Loraine, Robert K. (1994) Project specific partnering. Engineering, Construction and Architectural Management, 1, 5-16.

Marquardt, Michael J. (1996) Building the Learning Organization. McGraw-Hill, New York

Matthews, Jason, Tyler, Alan and Thorpe, Antony (1996) Pre-construction project partnering: developing the process. Engineering, Construction and Architectural Management, 1-2, 117-131. 
Nyberg, Tom, Pahkala Samuli and Wegelius-Lehtonen Tutu (1997) Benchmarking as a tool for developing order-delivery processes in a multinational company. Proceedings, NORDNET'97, Iceland.

Shonberger, Richard J. (1986) World Class Manufacturing. Free Press, New York. Wegelius-Lehtonen, Tutu and Pahkala, Samuli (1995) Case example of partnering in the construction industry. Proceedings, NOFOMA, Oslo.

Wilson, Roger A., Songer, Anthony D. and Diekmann, James (1995) Partnering: More Than a Workshop, a Catalyst for Change. Journal of Management in Engineering, September/October 1995, 40-45. 